\title{
Application of integrative information system improves the quality and effectiveness of cancer case management
}

This article was published in the following Dove Press journal:

Journal of Multidisciplinary Healthcare

9 June 2015

Number of times this article has been viewed

\author{
Pei-Yi Lee ${ }^{1,2}$ \\ Tsue-Rung Chang' \\ 'Department of Nursing, MacKay \\ Memorial Hospital, Taipei, Taiwan; \\ ${ }^{2}$ Department of Nursing, MacKay \\ Medical College, Taipei, Taiwan
}

Correspondence: Pei-Yi Lee Department of Nursing, MacKay Memorial Hospital, 45, Minsheng Road, Tamsui District, New Taipei City, Taiwan Email cheryl3507@gmail.com

\begin{abstract}
Cancer case management provides consecutive care during the entire process through diagnosis to treatment and follow-up. We established an integrative information system with integration of the health information system. This integrative information system shortened the time spent on case screening, follow-up data management, and monthly data summarization of case managers. It also promoted the case follow-up rate. This integrative information system may improve the quality and effectiveness for cancer case management, one important part of cancer nursing.
\end{abstract}

Keywords: cancer, case management, integrative information system

\section{Introduction}

According to definition by the Case Management Society of America, case management (CM) is a collaborative process of assessment, planning, facilitation, care coordination, evaluation, and advocacy for options and services to meet an individual's and family's comprehensive health needs through communication and available resources to promote quality, cost-effective outcomes. CM has been proven effective to help improve disease control and care quality in many clinical fields, such as improve glycemic control in diabetic patients ${ }^{1,2}$ and clinical outcomes in HIV/AIDS patients. ${ }^{3,4}$ The application of $\mathrm{CM}$ in the oncology field could be referred to as cancer case management (CCM).

Cancer has been the leading cause of death in many countries. ${ }^{5}$ Management of cancer patients consists of medical treatment, nursing care, and other expertise as a multidisciplinary team work. Among nursing care, the CM, defined as an integration of interdisciplinary expertise to provide a comprehensive management process for each individual case, plays an important role in bridging and coordinating each profession in disease management including cancer.

In current clinical practice, each cancer case manager has to manage more than 400 cases simultaneously in Taiwan, ${ }^{6}$ which might be far beyond the caseload in other countries. As the enrollment period keeps progressing, the number of accumulated cases rapidly grows. This great quantity of cases might prolong the management time for case screening, follow-up, and periodical data summarization, etc. Depth and details of CM may also be compromised. Given that caseload size may affect the quality of care, ${ }^{7}$ the growing caseload size may need the aid of computerized information systems to improve the quality of CCM.

To improve effectiveness and quality of data management, including the processing time, the development of customized information systems in each institution is 
an important trend. For example, $\mathrm{Wu}$ and Lin reported an improvement in cancer screening model by using an integrated operating system. ${ }^{8}$ The clinical unmet nursing need in CCM is that no available computerized tool to aid clinical practice for the growing caseload size has been developed. To solve this problem, we developed an integrative information system (IIS) dedicated to CCM in our institution. After preliminary test and revision, this IIS has been adopted for daily practice of CCM since 2008. The research objective was to establish a practical tool for unmet nursing need in CCM and to validate the effectiveness by scientific methodology.

In this study, we established the IIS and collected the detailed data during processing of CCM and compared the management results before and after administration of this IIS to justify its application.

\section{Methods}

\section{Development of IIS}

Based on the central theme of patient-centered care, we designed a computer program, namely IIS, to manage case data with a user-friendly interface for case managers (Figure 1). During the processing of program design, suggestions and comments from eight cancer case managers were adopted for in-depth and detailed revision. For programming, the Visual Basic.NET (VB.NET) 2003 from Microsoft (Microsoft Corporation, Redmond, WA, USA) was used. To construct the framework of this IIS, the considerations, such as needed user functions, systematic requirement, software specification, work flow connection, and clinical CM planning were included. The designed functions of IIS contained two major domains, the new case search and case database establishment. To facilitate data search by the case manager, the ActiveX Data Objects interface was designed. Single Sign-on was used for specific registration. The hospital information system was established by using Oracle 11.2.0.4, Hyperion Intelligence 8.3 through Structured Query Language and was written by VB.NET 2003, VB5 and C\#. It was integrated to IIS to enhance the processing and operation efficiency of case managers.

\section{Verification, error detection, system improvement, execution and auditing of IIS}

During the initial execution period of IIS by cancer case managers, the system verification, error detection and correction had been performed. The user manual was edited subsequently with detailed instruction for users. For improvement of this IIS, the user meetings were held bi-annually
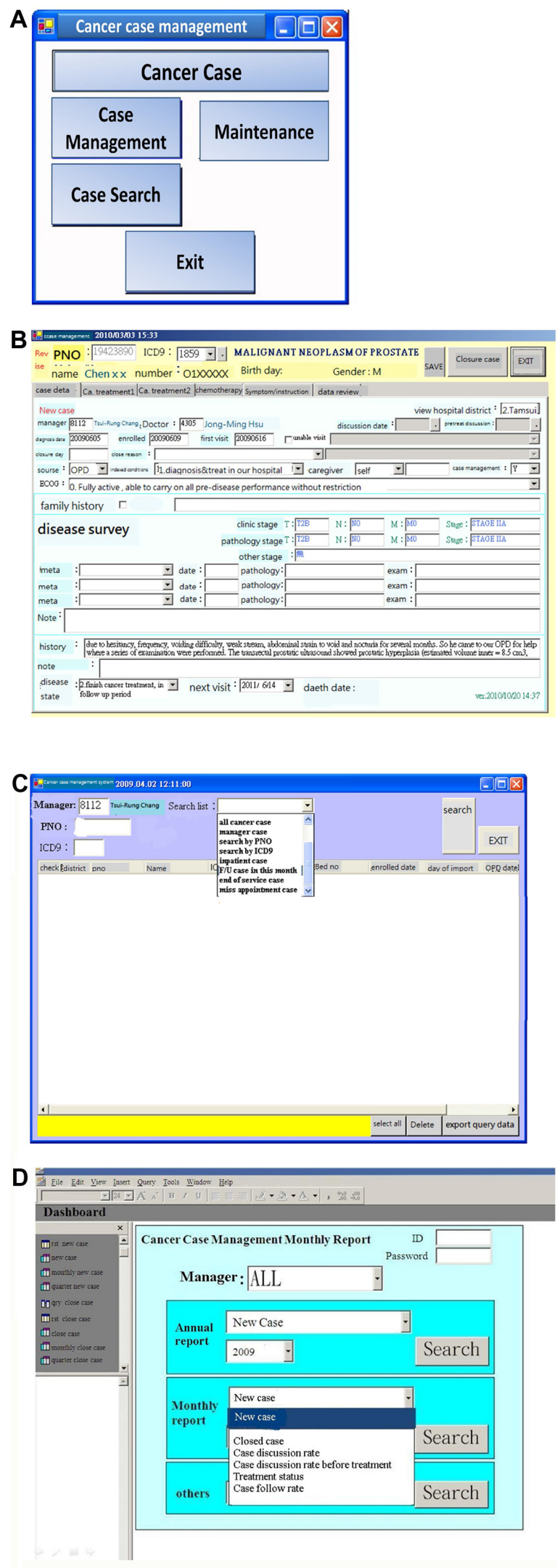

Figure I Demonstration of representative interfaces of integrative information system for cancer case management.

Notes: (A) System maintenance and general information. (B) Case management and medical information. (C) Case follow-up information. (D) Data analysis and reporting. 
to collect practical issues and problems related to $\mathrm{CM}$ and system operation. The audit, information collection, and data analysis were executed in terms of the following categories: case screening, CM, quality of care, efficiency of management, and parameters of system processing.

\section{Statistics}

For statistical analyses, the Student's $t$-test was performed using the software package SPSS 12.0 (SPSS Inc., Chicago, IL, USA).

\section{Results \\ Processing time}

By using this IIS, case mangers shortened the time spent on case screening, follow-up data management, and monthly data summarization from 8.32 to 1.25 minutes, 3.95 to 0.64 minutes and 3.54 to 1.15 minutes per case, respectively. As demonstrated in Table 1, the greatest improvement of processing time in case screening could be noted in managing cases of gynecological cancer. For time spent on follow-up data management and monthly data summarization, the greatest shortening was those for head and neck cancer as well as lung cancer, respectively.

\section{Follow-up rate}

The case follow-up rate in all categories of cancer cases was augmented from $92 \%$ to $99 \%$. Within these managed cases, the most beneficial effect on follow-up rate by using IIS was noted in cases of head and neck cancer (Table 1).

\section{Discussion}

In this study, we established a computerized system with integration of $\mathrm{CM}$ and the hospital information system for clinical practice of CCM. The preliminary experience for operating this system demonstrates the feasibility and improvement of CCM processing. Furthermore, the clinical outcome of cancer case follow-up rate was increased.

According to literature survey and to our best knowledge, the information system for CM focusing on cancer patients remains limited..$^{9-11}$ The establishment of this IIS was based on the need from clinical practice and might be the first one dedicated to CCM.

In processing CCM by using this IIS, we found that the most evident improvement of the time spent on case screening, follow-up data management, and monthly data summarization were those for gynecological, head and neck, and lung cancers. The possible correlation with complexity of treatment modalities, high recurrence rates, prolonged clinical course, and this improvement could be considered. For increase in follow-up rate, the greatest improvement was in management of head and neck cancer patients. It is our understanding that social activity withdrawal due to body image alteration or speech function impairment in head and neck cancer patients has been reported. ${ }^{12}$ By using this IIS, the cancer case managers may create more time and get more precise follow-up schedules for cancer cases of this category. Extension of this information system to palliative care service may augment the clinical significance in CM of cancer patients. ${ }^{13-15}$

The limitation and drawback of this IIS remains to be improved in terms of clinical operating interface, work flow fluency, and integration with other information systems. We have been working on this issue during clinical practice of CCM.

The nursing implication of this study is that the IIS could improve the quality and effectiveness for CCM, one important part of cancer nursing.

Table I The processing time for cancer case management and patient follow-up rate before and after application of the integrative information system

\begin{tabular}{|c|c|c|c|c|c|c|c|c|}
\hline \multirow[t]{3}{*}{ Cancer type } & \multicolumn{2}{|l|}{ Case screen } & \multicolumn{2}{|c|}{$\begin{array}{l}\text { Follow-up data } \\
\text { management }\end{array}$} & \multicolumn{2}{|c|}{ Data summarization } & \multicolumn{2}{|c|}{ Follow-up rate (\%) } \\
\hline & Before & After & Before & After & Before & After & Before & After \\
\hline & $\begin{array}{l}\text { Time } \\
\text { (min/case) }\end{array}$ & $\begin{array}{l}\text { Time } \\
\text { (min/case) }\end{array}$ & $\begin{array}{l}\text { Time } \\
\text { (min/case) }\end{array}$ & $\begin{array}{l}\text { Time } \\
\text { (min/case) }\end{array}$ & $\begin{array}{l}\text { Time } \\
\text { (min/case) }\end{array}$ & $\begin{array}{l}\text { Time } \\
\text { (min/case) }\end{array}$ & $\begin{array}{l}\text { Time } \\
\text { (min/case) }\end{array}$ & $\begin{array}{l}\text { Time } \\
\text { (min/case) }\end{array}$ \\
\hline Head and neck & 10.38 & 1.43 & 5.00 & 0.65 & 3.33 & I.II & 87 & 100 \\
\hline Breast & 6.77 & 1.30 & 3.75 & 0.62 & 3.33 & 0.83 & 88 & 99 \\
\hline Lung & 8.28 & 1.25 & 4.39 & 0.73 & 4.29 & 1.25 & 97 & 100 \\
\hline Liver & 7.94 & 1.20 & 4.19 & 0.45 & 3.75 & 1.30 & 87 & 100 \\
\hline Colorectal & 6.82 & 1.25 & 3.37 & 0.52 & 3.00 & I.II & 98 & 99 \\
\hline Urinary system & 8.57 & 1.25 & 3.95 & 0.78 & 3.75 & $\mathrm{I} .43$ & 99 & 99 \\
\hline Gynecologic & 9.47 & 1.05 & 3.33 & 0.76 & 3.33 & 1.00 & 91 & 99 \\
\hline Mean & 8.32 & $1.25^{*}$ & 3.95 & $0.64 *$ & 3.54 & $1.15^{*}$ & 92 & 99 \\
\hline
\end{tabular}

Note: $* P<0.05$ was regarded as significant statistical difference in comparison between the parameters before and after using the integrative information system. Abbreviation: min, minutes. 


\section{Disclosure}

The authors report no conflicts of interest in this work.

\section{References}

1. Aubert RE, Herman WH, Waters J, et al. Nurse case management to improve glycemic control in diabetic patients in a health maintenance organization. A randomized, controlled trial. Ann Intern Med. 1998; 129(8):605-612.

2. Krein SL, Klamerus ML, Vijan S, et al. Case management for patients with poorly controlled diabetes: a randomized trial. Am J Med. 2004; 116(11):732-739.

3. Wildeman MA, Zandbergen J, Vincent A, et al. Can an online clinical data management service help in improving data collection and data quality in a developing country setting? Trials. 2011;12:190.

4. Fraser HS, Jazayeri D, Nevil P, et al. An information system and medical record to support HIV treatment in rural Haiti. BMJ. 2004;329(7475): $1142-1146$.

5. Siegel R, Naishadham D, Jemal A. Cancer statistics, 2012. CA Cancer J Clin. 2012;62(1):10-29.

6. Wang CW. [The development and use of databases in case management]. Hu Li Za Zhi. 2009;56(2):28-32. Chinese.

7. Burns T, Yiend J, Doll H, Fahy T, Fiander M, Tyrer P. Using activity data to explore the influence of case-load size on care patterns. $B r J$ Psychiatry. 2007;190:217-222.
8. Wu PH, Lin WL. [Improving the cancer screening model: experience applying an integrated operating system]. Hu Li Za Zhi. 2009;56(6): 55-62. Chinese.

9. Wulff CN, Thygesen M, Sondergaard J, Vedsted P. Case management used to optimize cancer care pathways: a systematic review. $B M C$ Health Serv Res. 2008;8:227.

10. Goodwin JS, Satish S, Anderson ET, Nattinger AB, Freeman JL. Effect of nurse case management on the treatment of older women with breast cancer. J Am Geriatr Soc. 2003;51(9):1252-1259.

11. Wulff CN, Vedsted P, Sondergaard J. A randomised controlled trial of hospital-based case management to improve colorectal cancer patients' health-related quality of life and evaluations of care. $B M J$ Open. 2012;2(6). pii: e001481.

12. Danker H, Wollbruck D, Singer S, Fuchs M, Brahler E, Meyer A. Social withdrawal after laryngectomy. Eur Arch Otorhinolaryngol. 2010;267(4):593-600.

13. Back AL, Li YF, Sales AE. Impact of palliative care case management on resource use by patients dying of cancer at a Veterans Affairs medical center. $J$ Palliat Med. 2005;8(1):26-35.

14. Seow H, Piet L, Kenworthy CM, Jones S, Fagan PJ, Dy SM. Evaluating a palliative care case management program for cancer patients: the Omega Life Program. J Palliat Med. 2008;11(10):1314-1318.

15. van der Plas AG, Onwuteaka-Philipsen BD, van de Watering M, Jansen WJ, Vissers KC, Deliens L. What is case management in palliative care? An expert panel study. BMC Health Serv Res. 2012;12:163.
Journal of Multidisciplinary Healthcare

\section{Publish your work in this journal}

The Journal of Multidisciplinary Healthcare is an international, peerreviewed open-access journal that aims to represent and publish research in healthcare areas delivered by practitioners of different disciplines. This includes studies and reviews conducted by multidisciplinary teams as well as research which evaluates the results or conduct of such teams or health-

\section{Dovepress}

care processes in general. The journal covers a wide range of areas and welcomes submissions from practitioners at all levels, from all over the world The manuscript management system is completely online and includes a very quick and fair peer-review system. Visit http://www.dovepress.com/ testimonials.php to read real quotes from published authors. 